\title{
Genetical Studies on Skin Diseases
}

VI. Ehelides inversa (Siemens)

By

\section{Yoshio Yoshida \\ (吉田良夫)}

(From the Department of Dermatology, Faculty of Medicine, Tohoku University, Sendai. Director: Prof. M. I tô)

(Received for publication, October 11, 1951)

Report of Cases

Case 1.-K. T., a schoolboy, aged 17, suffered from pigmentary spots on the face, hands and feet. A few years after birth, the pigmentations first appeared on the lips and grew more marking gradually. In the school age he noticed pigmentations on the other parts of the body. Among his eight brothers and sisters, an elder sister, aged 25, suffered from highgrade freckles. There has been no disturbance in general health.

Status presens: There are typical freckles on the face. Most charakteristic is the pigment spots on the lips (Fig. 1) and buccal mucosa. They consist of numberous macules of dark brown or black colour, varying from 1 to several millimeters in diameter. Similar pigment spots, but in smaller size, are found on the hands and feet excepting insteps. They are most densely distributed on the volar side of the forefingers and thumbs, especially on their finger tips. But there is no abnormal pigmentation on the other parts of whole body.

Case 2.-T. K., an electric workman, aged 22, showed similar pigmentations as case 1. His pigmentary spots on the lips were noticed soon after birth and on the hands and feet at the age of three years. His parents, brother and sister present no pigmentary disturbance such as freckles.

Status presens: The distribution and characters of pigmentation as in case 1 (Fig. 2). And moreover, he has melanosis sklerae and lentigos on the back, hip, left forearm, penis and anal region.

Case 3.-T. I., a wife aged 31 had been noticed the pigmented spots on the under lip and buccal mucosa from her childhood. Her parents are related by blood. One of her brothers showed similar pigmentation on the underlip and her second daughter presented similar pigmented macules on the underlip and buccal mucosa (Fig. 3). 
Fig. 1 (case 1). Photograph showing characteristic pigmented macules on the lips.

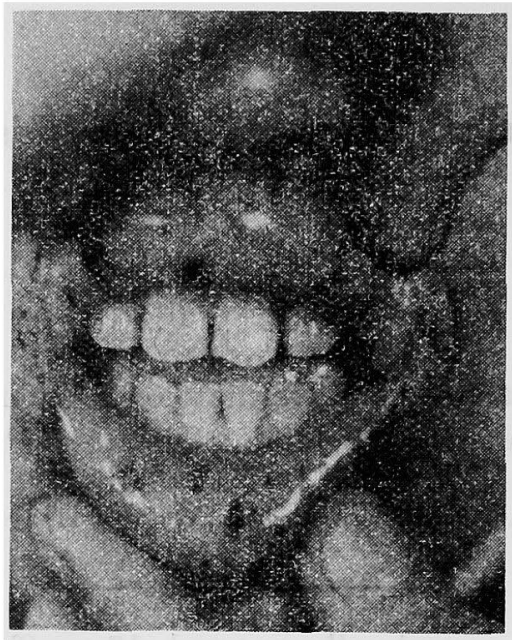

Fig. 2. (case 2). Photograph showing freckle-like pigmentations on the palms and fingers.

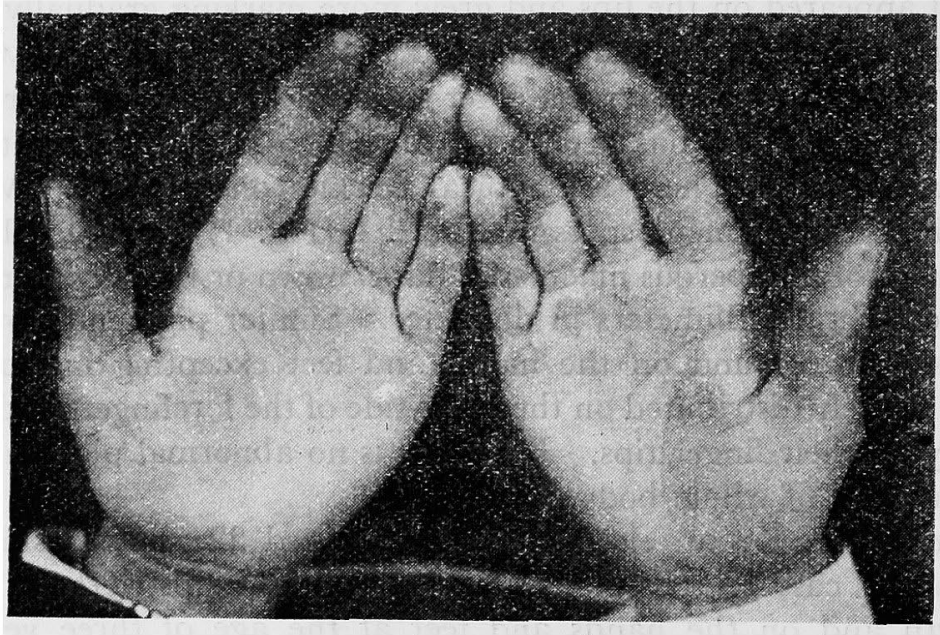

Fig. 3. Pedigree of case 3.

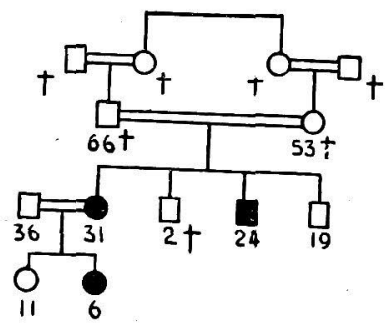


Status presens: There are found typical freckles on the face and frecklelike pigmentation on the fingers. About ten, dark brownish, pinheadsized spots on the underlip and three similar spots, but in larger size, on the buccal mucosa are admitted.

\section{Histology}

1) Case 1. A section removed from the volar side of left forefinger, shows the basal layer which contains numerous melanin granules. They are richest in crista profunda intermedia and some of basal cells present the form of dendritic cells. No melanin granules in derma. The nerve fibre staining preparates by Bielschowsky-Seto method show that there are rich in the nerve organs corresponding to this location, fingertip. Wagner-Meissner's, Vater-Paccini's corpuscles and some intraepidermal nerve fibres are admitted. A section from the underlip shows normal horny and granular layer but with somewhat irregular epidermal processes. Basal layer is laden with little pigment granules and somewhat disordered. Chromatophores are increased in number in the upper dermal layer. But there is no vevus-cell.

2) Case 2. A section from the volar side of the left little-finger presents the similar changes as in case 1 (Fig. 4). Section obtained from the underlip shows some intraepidermal vaculoes, polychromasia of pricklecell and irregular epidermal processes. Basal layer is laden with little melanin granules and some granules reach to the prickle layer. Chromatophores in the upper dermal layer take rounder form than those in case 1 and some of them present the figure like as so-called "Abtropfung" of the basal cell. But I cannot conclude that they are the typical nevuscells.

Fig. 4 (case 2). Section from the volar side of the left little-finger. Bielschowsky-Seto's staining. Wagner-Meissner's corpuscle is observed.

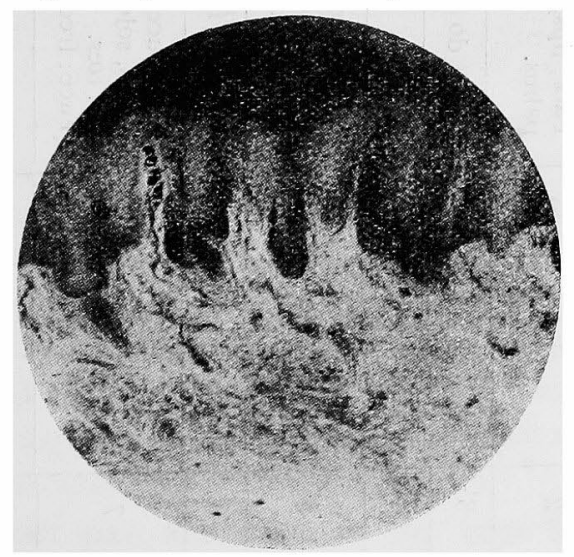




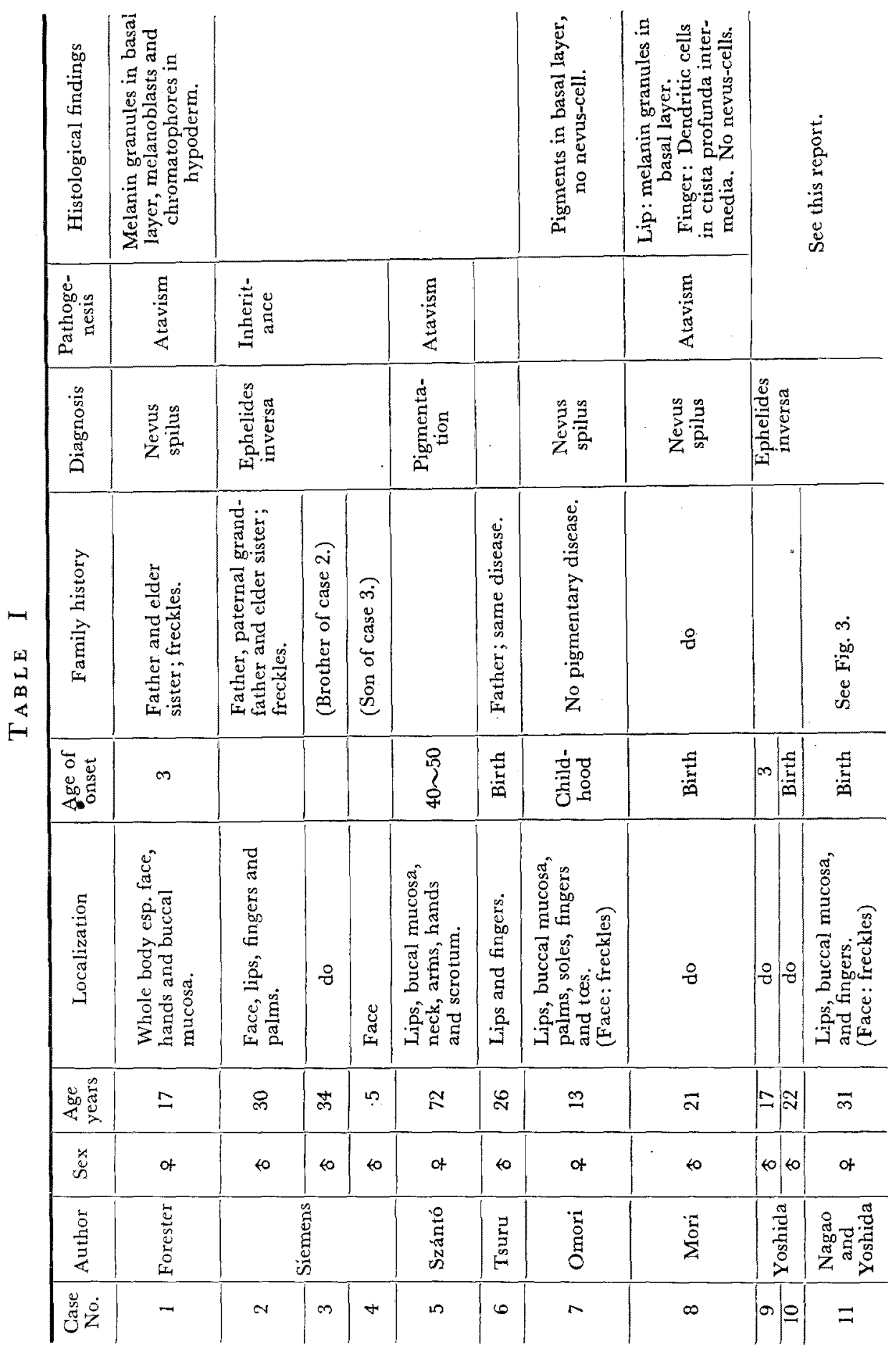




\section{Comment}

I collected 11 cases similar to above mentioned from the literature and summarized in Table I. Siemens diagnosed Foerster's') case and his three cases as new type of freckles and named them "ephelides inversa." But I can find only one case by Szántó, ${ }^{31}$ whose onset was very tardy, corresponding with this new type in foreign literature since that time. In Japan, on the other hand, I find six cases ${ }^{4(5) 6)}$ including three cases by myself. K. Kitamura mentioned at the 49th meeting of Japanese dermatological association that he had experienced one or two unreported cases of this type. It has been called attention that pigmentary diseases are more frequent in the yellow race than in the white and black races. This disease may be not so rare in our race too.

In these cases, the lesions are not always circumscribed to the area exposed to the light and heat of the sun. Siemens payed special attention to this fact and gave the important role to the inheritance in the pathogenesis of freckles. But his diagnosis, "ephelides inversa", become a subject of discussion. In the majority of these cases, high-grade freckles were noticed in the member of the families. And I think that Siemens' no. 4 case can be diagnosed as typical freckles judging from his description and photograph. From these facts, Siemens' diagnosis may partly be justified. But he thought it possible to differentiate ephelides and nevus spilus clinically and genetically. So he made his cases including no. 4 and Foerster's case the difference of degree in ephelides inversa. I cannot agree with him in this point. I think that Foerster's case nearly relate to nevus spilus rather than to ephelides. We experience sometimes the cases which make it defficult to differentiate between ephelides, nevus spilus and lentigines. And in these cases, family histories and histological findings cannot take a conclusive role. From above mentioned, I agree with Meirowsky ${ }^{7}$ ) who admitted the existence of transitions between ephelides and nevus spillus.

At all events, I cannot neglect the close relations between these cases and ephelides. And so, after admitting the existence of the transitional type, I agree with Siemens' naming, "ephelides inversa."

About the pathogenesis, the word of "atavism" was used by the authors, who diagnosed the case as nevus spilus. But this word, which had been misunderstood before the rediscovery of Mendel, cannot explain the pathogenesis. Thus, this problem remains unsolved. But about the special distribution of this pigmentations, I want to call attention to the fact that the lips, palms and soles coinside with each other about the conditions of horny layers and sensory nerves.

Anyway, we must pay attention to the next facts: (1) "Hetero- 
chromie" has the danger of malignant change, (2) the localization of pigment spots in these cases coinsides with the site of predilection of melanocarcinoma and (3) these regions are exposed to the external irritations at all times.

\section{Summary and Conclusions}

Three cases with the pigmentations in the face, lips, buccal mucosa, hands and feet were reported.

Similar cases were collected from the literature, and discussed their relations with ephelides and nevus spilus.

Admitting the existence of transitional form between ephelides and nevus spilus, I agreed with the Siemens' diagnosis, " ephelides inversa."

\section{References}

1) Foerster, Dermat. Wschr., 19286, 83, 1435.

2) Siemens, Dermat. Zschr., 1928, 53, 373.

3) Szántó, Dermat. Wschr., 1936, 102, 24.

4) Tsuru, Hifu-to-Hitsunyo (Dermat. and Urol.), 1936, 4, 748.

5) Omori, Hifuka-Seibyoka Zasshi (Jap. J. Dermat. and Ven.), 1942, 52, 246.

6) Mori, Rinsho-Hifu-Hitsunyo (Clinical Dermat. and Urol.), 1948, 2, 215.

7) Meirowsky, Jadassohns Handb., 1933, IV/2, 653. 